SHORT REPORT

\title{
Prospective audit of 106 consecutive human bite injuries: the importance of history taking
}

\section{G Wallace, C E Robertson}

Emerg Med J 2005;22:883-884. doi: 10.1136/emj.2004.021246

Objectives: Some patients attempt to conceal human bites with factitious mechanisms of injury. Follow up questioning allows patients to modify their histories. This practice was prospectively audited.

Methods: Patients with cutaneous wounds who did not present with a history of human bite were asked a follow up question. Those who then gave a history of human bite were noted.

Results: Certain groups of patients with human bites were significantly more likely to provide a factitious history and/or delay presentation.

Conclusion: Follow up questioning dramatically increased the case-detection rate, prompting specific management.

$\mathrm{H}$ uman bite injuries (HBIs) are distinct from simple cutaneous wounds due to their potential bacterial and viral sequelae. ${ }^{1-4}$ Some patients may attempt to conceal the source of their injuries, making HBI specific treatment less likely. ${ }^{5}$

\section{METHODS}

We conducted a prospective audit of patients presenting consecutively to the Edinburgh adult Accident and Emergency (A\&E) department from 1 October 2001 for 171 days. The Edinburgh A\&E department serves a catchment population of approximately 554000 adults (older than 13 years) in the Midlothian region of Scotland. ${ }^{6}$ We used a predesigned proforma to collect the data which included the characteristics of the injury and basic patient demographics and, where known, adversaries. All direct referrals to specialties were also included in the audit.

Patients with cutaneous injuries who did not present with a history of human bite were asked a follow up question similar to: "Could this wound have been caused by a bite or on someone's teeth? I am asking specifically since, as you may know, such wounds may have a higher risk of infection." Some patients then retracted their presenting history, declaring an HBI.

We recorded the HBIs as either "occlusions" ( the adversary bit the patient) or "strikes" (the patient hit an adversary in the mouth). Histories were either "pre-question" (patients declared the HBI in their presenting history) or "postquestion" (patients declared the HBI only after the follow up question). We classified the HBIs as "infected" if they caused one or more of: abscess, lymphangitis, wound associated erythema, wound associated swelling, purulent wound drainage, or systemic pyrexia. ${ }^{7}$ Self-inflicted bites were excluded.

Statistical analyses were tested for significance at the 0.05 level by $\chi^{2}$ tests with $95 \%$ confidence intervals (CI) for categorical data, and the Mann-Whitney U test (MWT) for continuous data (SPSS for Windows Release 11.0).

\section{RESULTS}

A total of 77 males and 23 females, mean age 26.9 years (range 13-61), sustained 106 HBIs over 171 days, giving an annual incidence of 45.1 HBIs per 100000 catchment population. Of the total $106 \mathrm{HBIs}, 37$ were strikes, which occurred in 33 males and 3 females (1 patient sustained 2 strikes), and 69 were occlusions, which occurred in 44 males and 20 females ( 5 patients sustained 2 occlusions). Most injuries (88/106) were clinically uninfected at presentation.

A total of 62 patients gave pre-question histories, but a significant proportion $\left(\chi^{2}: 38 / 100, p<0.05 ; 95 \% \mathrm{CI}=28.5 \%\right.$ to $47.5 \%$ ) declared an HBI only after the follow up question. Those who gave pre-question histories presented significantly more quickly (MWT: $p<0.01, z=-3.21$; pre-question: median 1.8 hours post-injury, interquartile range (IQR) 1.0-5.5 hours; post-question: median 11.0 hours post-injury, IQR 1.5-24.6 hours). Forty five patients knew their adversaries personally: 27/45 adversaries had bitten them, and patients had struck $18 / 45$ adversaries. Patients who gave post-question histories were significantly more likely to know their adversaries personally $\left(\chi^{2}: 23 / 38, \quad p<0.05 ; 95 \%\right.$ $\mathrm{CI}=45.0 \%$ to $76.1 \%)$. Patients with occlusions were significantly more likely to provide pre-question histories $\left(\chi^{2}\right.$ : $45 / 64, \mathrm{p}<0.05 ; 95 \% \mathrm{CI}=59.1 \%$ to $81.5 \%$ ), whereas those with infected wounds were significantly more likely to give postquestion histories $\left(\chi^{2}: 13 / 18, \mathrm{p}<0.01 ; 95 \% \mathrm{CI}=51.5 \%\right.$ to $92.9 \%)$.

Four patients presented solely for assessment of minor head injuries, and only when other undeclared cutaneous injuries were found on routine examination did they volunteer that these were HBIs. Twelve patients presented specifically to ask about viral transmission; six of the known adversaries were considered "high risk", of which two had hepatitis C and/or human immunodeficiency virus (HIV) infection.

\section{DISCUSSION}

It has long been recognised that some patients attempt to conceal HBIs with factitious histories for various reasons, ${ }^{5}$ but the frequency of, and the patient groups susceptible to, this behaviour have never before been identified. HBIs are common in our catchment population with an annual incidence of 45.1 per 100000 , contrasting sharply with the only previously published value of 11.8 per 100000 from New York City. ${ }^{8}$ This may represent a true increase in the incidence of HBIs, but more likely reflects environmental factors or underreporting. ${ }^{8}$ Well over a third of patients in our audit failed to give an appropriate history of HBI, yet the true incidence may be even higher since some patients may not respond to follow up questioning and some will not present to A\&E.

HBIs usually occur during assaults. Patients may feel that admitting strikes will label them as aggressors and offer plausible alternative histories to try to evade repercussions. Conversely, a patient bitten by someone they know may feel 
uncomfortable implicating their assailant. Biting is a common method of non-accidental injury and clinicians should be aware of their common topographic features. ${ }^{59}$ Accurate and thorough documentation of suspected or declared HBIs is necessary, and helpful guidelines on their management are available. ${ }^{1}$

Patients who gave post-question histories delayed their presentation significantly, increasing their susceptibility to destructive bacterial complications. ${ }^{5}{ }^{10}$ Twelve patients presented specifically for advice regarding viral transmission, and of these, 10 were employed by educational, medical, or police establishments. Patients who know their adversary personally may be able to provide useful information for assessing whether viral postexposure prophylaxis is indicated. They should receive specialist counselling and follow up (for example, from infectious diseases personnel). Unfortunately, we found that patients who knew their adversaries were significantly less likely to declare the HBI in their presenting histories.

\section{CONCLUSIONS}

HBIs are commonly seen in A\&E. In patients who do not volunteer a history of HBI, specific follow up questioning may increase the case detection rate and allow specific management to commence without further delay. A high index of suspicion is necessary to identify HBIs in patients who remain guarded about the mechanism.

\section{ACKNOWLEDGEMENTS}

We would like to thank Jenny Henry (Department of Statistics, Scottish Trauma Audit Group) for her help with statistical analyses.

\section{CONTRIBUTORS}

$C$ Wallace initiated and conducted the audit, analysed the data, and wrote the paper. C Robertson supervised the audit, and edited and contributed to the writing of the paper. C Wallace and C Robertson are both guarantors for the paper and its content.

\section{Authors' affiliations}

C G Wallace, Department of Plastic and Reconstructive Surgery, Queen Victoria Hospital, East Grinstead, West Sussex, UK
C E Robertson, Department of Accident and Emergency Medicine, Royal Infirmary, Edinburgh, UK

Competing interests: none declared

Ethical approval was not required for this study. It is well documented that some patients who have sustained human bites give alternative presenting histories to explain their injuries in an attempt to conceal the mechanism. This may be for a variety of reasons. Our Accident and Emergency Department has historically tried to address this problem with follow up questioning, allowing patients to clarify their presenting history. Occasionally patients retract their initial presenting history and give that of a human bite. These are questions that we would normally expect clinicians to ask, even before we conducted this audit. This was purely an audit study which did not change the way patients' histories were taken, the way patients were questioned, or the way patients were managed.

Correspondence to: $\mathrm{Mr}$ C G Wallace, Department of Plastic and Reconstructive Surgery, Queen Victoria Hospital, East Grinstead, West Sussex, RH19 3DX, UK; c.g.wallace@gmail.com

Accepted for publication 12 January 2005

\section{REFERENCES}

1 PRODIGY. PRODIGY Guidance-Bites-human and animal. Newcastle: Sowerby Centre for Health Informatics. Available at www.prodigy.nhs.uk/ guidance.asp?gt= Bites\%20-\%20human\%20and\%20animal laccessed 6 October 2004).

2 Andreo SMS, Barra LAC, Costa $\amalg$, et al. HIV type 1 transmission by human bite. AIDS Res Hum Retroviruses 2004;20:349-50.

3 Cancio-Bello TP, de Medina M, Shorey J, et al. An institutional outbreak of hepatitis B related to a human biting carrier. J Infect Dis 1982;146:652-6.

4 Dusheiko GM, Smith M, Scheuer PJ. Hepatitis C virus transmitted by human bite. Lancet 1990;336:503-4.

5 Perron AD, Miller MD, Brady WJ. Orthopedic pitfalls in the ED: fight bite. Am J Emerg Med 2002;20:114-17.

6 Registrar General for Scotland. Table 3 Estimated population by sex, five year age group and administrative area; 30 June 2002. Edinburgh: General Register for Scotland 2003. Available at www.gro-scotland.gov.uk/grosweb/ grosweb.nsf/pages/file7/\$file/02-pop-est-tab3.xls (accessed 6 October 2004)

7 Talan DA, Citron DM, Abrahamian FM, et al. Bacterial analysis of infected dog and cat bites: Emergency Medicine Animal Bite Infection Study Group. N Engl J Med 1999;340:85-92.

8 Marr JS, Beck AM, Lugo JA. An epidemiologic study of the human bite. Public Health Rep 1979;94:514-21.

9 Pretty IA, Hall RC. Forensic dentistry and human bite marks: issues for doctors. Hosp Med 2002;63:476-82.

10 Phair IC, Quinton DN. Clenched fist human bite injuries. J Hand Surg [Br] 1989; 14:86-7. 